\title{
Tables, Figures and Images
}

\section{Tables}

2.1 Participants' demographic data and CLIL experience 17

3.1 Demographic information for participants 37

3.2 Descriptive statistics for individual differences of respondents 39

3.3 Frequency of responses for independent variables 40

3.4 One-way ANOVA: Emotional burnout by school setting $\quad 40$

3.5 Pairwise comparisons: Emotional burnout by school setting 41

3.6 Correlation matrix for independent variables 41

3.7 ELS subscale coefficients for emotional burnout, controlled for gender and teaching experience

3.8 ELS subscale coefficients for job satisfaction, controlled for gender and teaching experience

5.1 Metaphors used by the ESL teachers during each stage of the AR programme (Interviews 1-5) 78

6.1 Interview participants' demographic and resilience data $\quad 97$

8.1 Demographic information of teacher participants 136

8.2 Most frequently used emotionally charged words $\quad 139$

8.3 Emotionally charged discourse with single occurrence $\quad 149$

9.1 Textbook comparison 155

9.2 Areas of potential emotional labour $\quad 157$

10.1 Details of the participants 179

10.2 Means and SDs of English teaching anxiety after training sessions

10.3 Means and SDs of programme satisfaction after training sessions

13.1 Elizabeth's stressors, silver linings and appraisal scores 239

15.1 Correlation analysis between motivation dimensions, TEI factors, experience, proficiency and age

15.2 The effect of gender on the motivation dimensions (mean ranks) 
15.3 The effect of the status of English (L1/LX) on the motivation dimensions (mean ranks)

\section{Figures}

3.1 Burnout spiral of FL teacher emotional labour (Acheson et al., 2016)

6.1 A resilience system 94

6.2 Distribution of adjusted resilience scores 97

$\begin{array}{ll}6.3 \text { Peter's resilience system } & 104\end{array}$

$\begin{array}{ll}6.4 & 105\end{array}$

7.1 The default mode network processes self-referential and socio-referential mind-time phenomena

10.1 A sample graph indicating the fluctuations in anxiety regarding the teaching of English over time

10.2 Levels of English teaching anxiety among the participants

10.3 Levels of programme satisfaction among the participants

10.4 Fluctuation of English teaching anxiety of Shika, a junior teacher

10.5 Fluctuation of English teaching anxiety of Moji, a junior teacher

10.6 Fluctuation of English teaching anxiety of Nami, a teacher with eight years' teaching experience

10.7 Fluctuation of English teaching anxiety of Naka, a junior teacher

10.8 Fluctuation of Moji's English teaching anxiety and satisfaction levels with the intervention programme

10.9 Fluctuation of Tana's English teaching anxiety and satisfaction levels with the intervention programme

14.1 The compass of emotion

\section{Images}

9.1 Listening exercise (On the Go: 22) 160

9.2 Role play (On the Go: 22) 161

9.3 Personal questions (On the Go: 23) 161

9.4 Your turn (On the Go: 19) 163

14.1 Inside the well of emotional well-being 248 